\title{
Analisis Video Like to Like Ratio Tiktok Pada \\ 5 Brand Sepatu Olahraga di Dunia
}

\author{
I Gede Nova Widyantara \\ STIMIK STIKOM Indonesia \\ igedenopa@gmail.com
}

\begin{abstract}
ABSTRAK
TikTok is a social media application launched by a Chinese company. TikTok allows users to create videos that are 15-60 seconds long accompanied by music, filters, and several other creative features. In Indonesia, there are 100 million active users, making Indonesia the country with the largest TikTok users in the world. The large number of active TikTok users in Indonesia can certainly provide an opportunity for brands to make the TikTok platform a social media marketing platform. There are 5 sports shoe brands in the world that use TikTok as a marketing platform, namely: Addidas, Nike, Reebok, New Belance, Airwalk. The purpose of this study is to calculate the credibility of the performance of several TikTok accounts of 5 Sports Shoes Brands in the World. The method used for this research is quantitative exploratory method. The results of this study indicate that it is the Addidas shoe vendor who gets the first rank and has good account performance credibility.
\end{abstract}

\begin{abstract}
ABSTRAK
TikTok merupakan salah satu aplikasi sosial media yang diluncurkan oleh perusahaan yang berasal dari Tiongkok. TikTok memungkinkan penggunanya untuk membuat video yang berdurasi 15-60 detik yang disertai dengan musik, filter, dan beberapa fitur kreatif lainnya. Di Indonesia terdapat 100 juta pengguna yang aktif sehingga menjadikan Indonesia sebagai negara dengan pengguna TikTok terbesar di dunia. Banyaknya jumlah pengguna TikTok yang aktif di Indonesia tentu dapat memberikan peluang bagi brand untuk menjadikan platform TikTok sebagai platform social media marketing. Adapun 5 Brand Sepatu Olahraga di Dunia yang memanfaatkan TikTok sebagai platform marketing, yaitu : Addidas, Nike, Reebok, New Belance, Airwalk. Tujuan dari penelitian ini yaitu untuk menghitung kredibilitas dari performa beberapa akun TikTok 5 Brand Sepatu Olahraga di Dunia. Metode yang digunakan untuk penelitian ini yaitu metode eksploratif kuantitatif. Hasil dari penelitian ini menunjukan bahwa vendor sepatu Addidas yang mendapatkan peringkat pertama dan memiliki kredibilitas performa akun yang baik.
\end{abstract}

Keyword : Credibility Account TikTok ; Social Media Promotion ; Social Media TikTok ; Video Like to Like Ratio ; Brand Sepatu Olahraga Di Dunia. 


\section{BAB I \\ Pendahuluan}

Perkembangan teknologi informasi dan komunikasi saat ini berkembang sangat pesat, hal ini didorong oleh bentuk baru dalam cara berkomunikasi serta berinteraksi melalui media sosial. Lahirnya media sosial menjadikan pola perilaku masyarakat mengalami pergeseran baik budaya, etikan dan norma yang ada (Cahyono, 2016). Komunikasi tidak hanya dapat dilakukan secara fisik, tetapi juga dapat dilakukan dengan menggunakan berbagai aplikasi media sosial di dunia maya. Keunggulan aplikasi sosial media adalah memberikan ruang komunikasi dua arah atau lebih antara konsumen-perusahaan dan konsumen-konsumen.

Perkembangan teknologi semakin pesat, banyak bermunculan media sosial dan berbagai macam aplikasi baru yang dijadikan ajang eksistensi seseorang untuk berbagi video, foto, maupun kegiatan sehari-hari kepada orang lain. Salah satunya adalah aplikasi TikTok yang banyak diminati oleh semua kalangan, mulai anak- anak hingga dewasa. Dengan efek music, stiker, serta 3D lainnya menjadikan aplikasi TikTok makin banyak diakses terutama oleh anak usia sekolah dasar samapai anak usia sekolah menengah atas (Chusna dkk., 2020)

Aplikasi TikTok kini menjadi salah satu platform sosial media yang cukup populer di kalangan masyarakat dunia. Jadi aplikasi Tik Tok adalah sebuah aplikasi jejaring sosial dan platform video music dimana pengguna bisa membuat, mengedit, dan berbagi klip video pendek lengkap dengan filter dan disertai musik sebagai pendukung. Dengan aplikasi ini, pengguna dapat membuat video pendek yang unik dengan cepat dan juga mudah untuk dibagikan dengan teman dan ke seluruh dunia (bambang winarso, 2021). Di Indonesia, terdapat 100 juta pengguna TikTok yang aktif sehingga menjadikan Indonesia sebagai negara dengan pengguna TikTok terbesar di dunia. Maraknya jumlah pengguna TikTok aktif di Indonesia tentu dapat memberikan peluang bagi brand untuk menjadikan platform ini sebagai platform social media marketing, contohnya seperti 5 Brand Sepatu Olahraga di Dunia, diantaranya yaitu : Addidas, Nike, Reebok, New Belance, Airwalk.

Penelitian ini menggunakan metode eksploratif kuantitatif, dan akan menghitung menggunakan ratio yang ada pada TikTok. Pada penelitian (I Putu Hendika Permana dan Ni Putu Suci Meinarni, 2021) menjelaskan bahwa terdapat 17 rasio yang ada pada sosial media TikTok dan relevan digunakan sebagai media ukur kredibilitas akun yang ada. Penelitian ini hanya berfokus untuk menghitung kredibilitas Video Like to Like Ratio pada 5 Brand Sepatu Olahraga di Dunia. Adapun 5 Brand Sepatu Olahraga di Dunia, diantaranya yaitu : Addidas, Nike, Reebok, New Belance, Airwalk (5 Brand Sepatu Olahraga di Dunia) menggunakan Video Like to Like Ratio. 


\section{BAB II \\ Tinjauan pustaka}

Perkembangan bidang teknologi berlangsung begitu cepat, melalui pengembangan terjadi dari waktu ke waktu yang mengarah pada munculnya aplikasi dan platform media. Masyarakat yang sedang berkembang, aplikasi yang banyak diminati oleh masyarakat saat ini antara lain : TikTok, Instagram, Twitter, WhatsApp, dll. Seperti yang terjadi, seiring berjalannya waktu aplikasi media sosial ini bisa menjadi candu masyarakat. Tidak hanya remaja, orang tua bahkan anak-anak yang menggunakan aplikasi media sosial dan aplikasi media sosial ini juga aktif digunakan.

Aplikasi Tik Tok adalah sebuah jaringan sosial dan platform video musik Tiongkok yang diluncurkan pada September 2016. Aplikasi tersebut membolehkan para pemakai untuk membuat video musik pendek mereka sendiri. Sepanjang kuartil pertama (Q1) 2018, TikTok mengukuhkan diri sebagai aplikasi paling banyak diunduh yakni 45,8 juta kali. Jumlah itu mengalahkan aplikasi populer lain semacam YouTube, WhatsApp, Facebook Messenger, dan Instagram Menurut Fatimah Kartini Bohang (dalam Wisnu, 2018). Dominan dari pengguna aplikasi Tik Tok di Indonesia sendiri adalah anak milenial, masih sekolah, dan orang tua (Mana, 2021).

Di Indonesia, fenomena anak muda dalam menggunakan TikTok menunjukan antusiasme yang sangat massif. Meraka berlomba membangun identitas demi mendapatkan citra yang diinginkan, seperti dipuji dan dikenal oleh banyak orang (Wijaya and Mashud 2020) . Aplikasi TikTok semakin populer sejak diluncurkan tahun 2016. Bahkan TikTok telah mencetak berbagai macam prestasi, salah satunya yaitu menyalip pendapatan iklan digital di negatanya yaitu pendapat Google China, Patio (Batam 2020) .

TikTok merupakan sebuah aplikasi yang menyajikan fitur membuat video disertai fitur efek yang sangat menarik dan mudah untuk digunakan. Dengan begitu, tidak sedikit para pebisnis online memanfaatkan kesempatan emas untuk menggunakan aplikasi TikTok sebagai platform untuk mengembangkan bisnis mereka melalui digital konten (Nusantara, 2021).

TikTok dianggap memiliki kekuatan atau pengaruh dalam industri, jadi tingkatkan kualitas akun dan tentukan kelas dan kredibilitas pemilik akun. Kredibilitas akun TikTok sangat penting bagi banyak orang minat. Kredibilitas akun TikTok dapat diukur dari tingkat kinerjanya secara matematis. Saat mengukur kinerja, ukurannya adalah termasuk dalam rasio. 


\section{BAB III \\ METODE PENELITIAN}

Penelitian ini menggunakan metode eksploratif kuantitatif untuk mengetahui kredibilitas dari performa akun TikTok 5 Brand Sepatu Olahraga di Dunia. Metode eksploratif yaitu akan menggali lebih dalam mengenai bagaimana pengaplikasian teori Uses and Gratification dalam jurnal - jurnal sebelumnya (Karunia H dkk., 2021).

Tujuan dari penelitian ini yaitu mengetahui nilai kredibillitas dari performa dari akun TikTok 5 Brand Sepatu Olahraga di Dunia. Ada beberapa langkah yang harus dilakukan dalam penelitian ini, sehingga mampu menemukan peringkat pertama akun TikTok Brand Sepatu Olahraga di Dunia memiliki performa yang terbaik . Langkah-langkah yang dilakukan pada penelitian ini, diantaranya yaitu :

1. Melakukan Eksplorasi Pada Website Untuk Menentukan Objek yang Akan Dianalisa.

Eksplorasi ini dilakukan pada beberapa halaman website yang menyediakan informasi mengenai objek yang akan di teliti. Setelah ekslorasi selesai dilakukan, sehingga ditemukan nama-nama Brand Sepatu Olahraga di Dunia yang akan dijadikan objek analisa. Setelah melakukan eksplorasi pada halaman website, maka langkah selanjutnya yaitu mencari nama akun TikTok dari masing-masing Brand Sepatu Olahraga tersebut. Pastikan semua Brand memiliki akun pada aplikasi sosial media TikTok.

\section{Menghitung Nilai Rata-Rata Variable Dari 5 Brand Sepatu Olahraga di Dunia.}

Pada langkah ke 2 ini, peneliti menghitung nilai variable video like to like views. Variabel merupakan salah satu unsur yang penting karena suatu proses pengumpulan fakta atau pengukuran dapat dilakukan dengan baik, bila dapat dirumuskan variabel penelitian dengan tegas (Nasution, 2017). Dalam menghitung nilai rata-rata dari variabel video like to like ratio yaitu dengan cara mengambil minimal 10 postingan kemudian di hitung sehingga menemukan nilai rata-rata dari masing-masing variable tersebut.

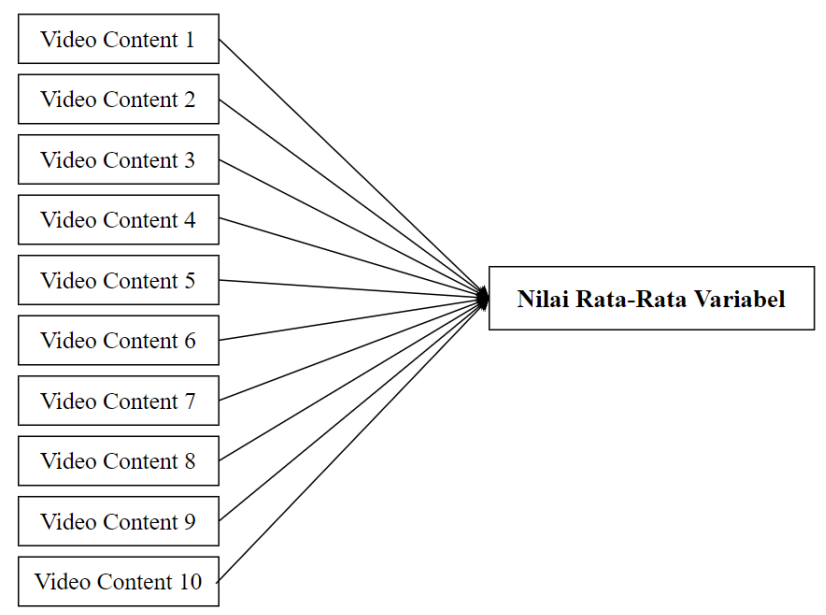

Gambar 1. Analisa Nilai Rata-Rata Variabel. 


\section{Menghitung Nilai Kredibilitas Rasio}

Dalam menghitung nilai kredibilitas dari video like to like ratio, peneliti ini menggunakan cara membagi nilai variabel pertama dengan nilai variabel kedua. Jika video like memiliki nilai 100 dan like ratio memiliki nilai 500, maka cara menghitungnya yaitu $100: 500=0,5$. Dengan begitu nilai dari video like to like ratio adalah 0,5 .

\section{Menentukan Peringkat Pada Akun TikTok}

Pada langkah ke 4 atau yang terakhir yang dilakukan pada penelitian ini yaitu menentukan peringkat pada masing-masing ratio yang ada. Pada penentuan peringkat perlu melihat karakteristik dari ratio yang di teliti. Jika karakteristik ratio merupakan yang terendah, maka objek yang memiliki nilai terendah akan mendapatkan angka 5 dan objek yang memiliki nilai tertinggi akan mendapatkan angka 1. Tetapi jika ratio memiliki karakteritik tinggi maka objek yang mendapatkan nilai tinggi akan mendapatkan angka 5 dan objek yang mendapatkan nilai terendah akan mendapatkan angka 1. Setelah mendapatkan hasil kredibilitas ratio maka dapat disimpulkan objek yang mana mendapatkan peringkat 1 sampai dengan peringkat 5 . 


\section{BAB IV \\ Hasil dan Pembahasan}

Akun Tiktok dari 5 brand sepatu olahraga di dunia

1. Addidas

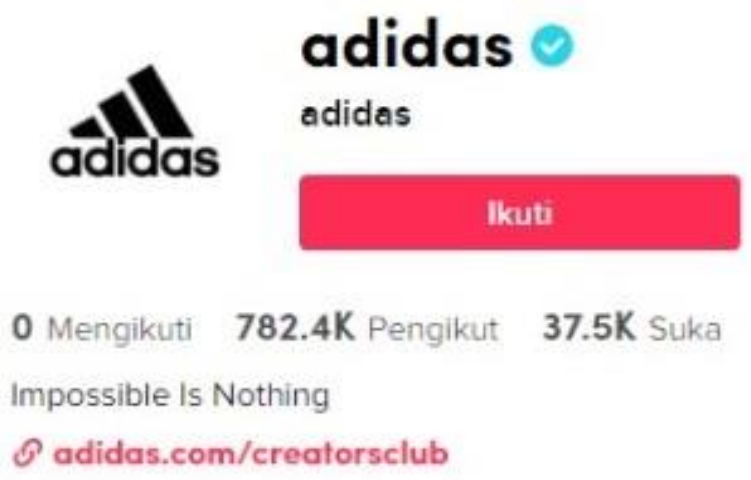

Sumber : https://www.tiktok.com/@adidas (akses pada 20-10-2021)

2. Nike

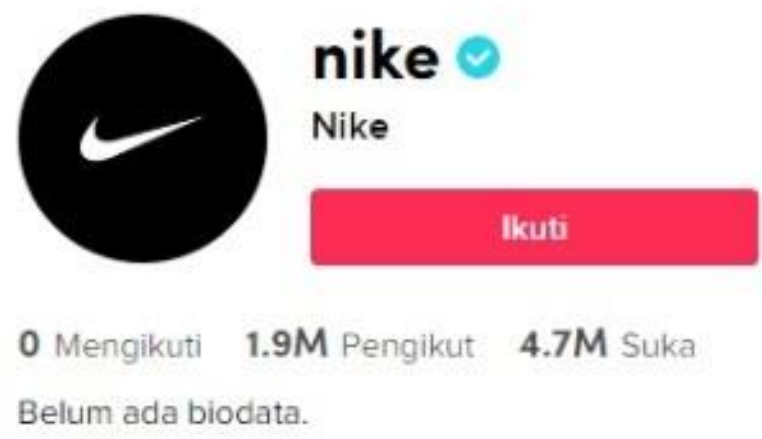

Sumber : https://www.tiktok.com/@nike (akses pada 20-10-2021) 
3. Reebok

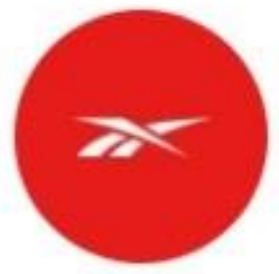

\title{
reebok
}

Reebok

\section{Ikuti}

39 Mengikuti $53.1 \mathrm{~K}$ Pengikut $1.2 \mathrm{M}$ Suka

The personality behind our brand.

o www.Reebok.com

Sumber : https://www.tiktok.com/@reebok (akses pada 20-10-2021)

4. New Belance

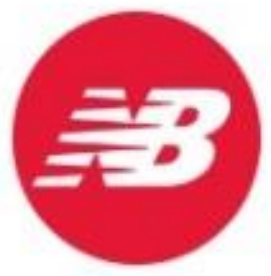

newbalance

New Balance

Ikuti

\author{
28 Mengikuti $126 \mathrm{~K}$ Pengikut $1.3 \mathrm{M}$ Suka \\ WE GOT NOW
}

Sumber : https://www.tiktok.com/@newbalance (akses pada 20-10-2021)

5. Airwalk

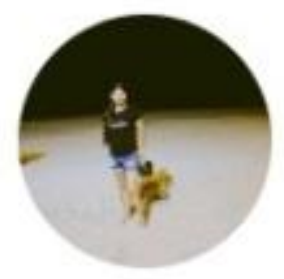

\section{airwalkshoes 234}

AIR WALK SHOES. e.c

\section{Ikuti}

\author{
2356 Mengikuti 2304 Pengikut 3498 Suka \\ Quito-Comite del Pueblo?
}

Sumber : https://www.tiktok.com/@airwalkshoes234 (akses pada 20-10-2021) 
Dari kelima akun Tiktok 5 brand sepatu olahraga di dunia, peneliti menemukan nilai dari masingmasing variable yang ada agar dapat menghitung Video Like to Like Ratio dari setiap akun. Pada akun Tiktok memiliki 7 variabel, diantaranya yaitu :

1. Likes

2. Followers (Pengikut)

3. Following (Mengikuti)

4. Video Likes

5. Video Comments

6. Video Share

7. Video Views

Dari ke 7 variabel tersebut penelita hanya fokus terhadap 2 varibel saja, yaitu :

1. Video Likes

2. Likes

Dari kedua variabel tersebut kemudian dianalisa sehingga menemukan nilai rata-rata dari variabel Video Likes dan variabel Likes Untuk menghitung nilai rata-rata dari variabel Video Likes dan variabel Likes yaitu dengan cara mengambil beberapa video sesuai yang postingan kemudian di hitung sehingga menemukan nilai rata-rata dari masing-masing variabel. Berikut merupakan tabel nilai rata-rata dari masing-masing 5 brand sepatu olahraga di dunia, yaitu :

Tabel 1. Analisa Nilai Rata-Rata Nilai Variabel Video Like dan Like Akun TikTok Addidas

Addidas

\begin{tabular}{|c|r|l|}
\hline No & Video Likes & Likes \\
\hline 1 & 6404 & 33.700 \\
\hline 2 & 3008 & \\
\hline 3 & 7932 & \\
\hline 4 & 16.300 & \\
\hline Total & $\mathbf{4 3 4 0 . 0 7 5}$ & $\mathbf{3 3 . 8 0 0}$ \\
\hline
\end{tabular}

Sumber : Pengolah Data excel 
Tabel 2. Analisa Nilai Rata-Rata Nilai Variabel Video Like dan Like Akun TikTok Nike

Nike

\begin{tabular}{|c|r|c|}
\hline No & Video Likes & Likes \\
\hline 1 & 1206 & 4.700 .000 \\
\hline 2 & 1661 & \\
\hline 3 & 1227 & \\
\hline 4 & 2706 & \\
\hline 5 & 2860 & \\
\hline 6 & 1785 & \\
\hline 7 & 1916 & \\
\hline 8 & 2321 & \\
\hline 9 & 6009 & \\
\hline 10 & 2075 & \\
\hline Total & $\mathbf{2 3 7 6 . 6}$ & $\mathbf{4 . 7 0 0 . 0 0 0}$ \\
\hline
\end{tabular}

Sumber : Pengolah Data excel

Tabel 3. Analisa Nilai Rata-Rata Nilai Variabel Video Like dan Like Akun TikTok Reebok

Reebok

\begin{tabular}{|c|r|c|}
\hline No & Video Likes & Likes \\
\hline 1 & 110 & 1.200 .000 \\
\hline 2 & 60 & \\
\hline 3 & 60 & \\
\hline 4 & 196 & \\
\hline 5 & 109 & \\
\hline 6 & 80 & \\
\hline 7 & 95 & \\
\hline 8 & 5746 & \\
\hline 9 & 62.100 & \\
\hline 10 & 1166 & \\
\hline Total & $\mathbf{7 6 8 . 4 1}$ & $\mathbf{1 . 2 0 0 . 0 0 0}$ \\
\hline
\end{tabular}

Sumber : Pengolah Data excel 
Tabel 4. Analisa Nilai Rata-Rata Nilai Variabel Video Like dan Like Akun TikTok New Belance

New Balance

\begin{tabular}{|c|r|c|}
\hline No & Video Likes & Likes \\
\hline 1 & 29.300 & 1.300 .000 \\
\hline 2 & 100.400 & \\
\hline 3 & 120.000 & \\
\hline 4 & 68.900 & \\
\hline 5 & 25.500 & \\
\hline 6 & 38.000 & \\
\hline 7 & 64.800 & \\
\hline 8 & 204.000 & \\
\hline 9 & 349.900 & \\
\hline 10 & 307.700 & \\
\hline Total & $\mathbf{1 3 0 . 8 5}$ & $\mathbf{1 . 3 0 0 . 0 0 0}$ \\
\hline
\end{tabular}

Sumber : Pengolah Data excel

Tabel 5. Analisa Nilai Rata-Rata Nilai Variabel Video Like dan Like Akun TikTok Airwalk Airwalk

\begin{tabular}{|c|r|r|}
\hline No & Video Likes & Likes \\
\hline 1 & 20 & 3441 \\
\hline 2 & 14 & \\
\hline 3 & 24 & \\
\hline 4 & 23 & \\
\hline 5 & 32 & \\
\hline 6 & 222 & \\
\hline 7 & 224 & \\
\hline 8 & 14 & \\
\hline 9 & 13 & \\
\hline 10 & 15 & \\
\hline Total & $\mathbf{6 0 . 1}$ & $\mathbf{3 4 4 1}$ \\
\hline
\end{tabular}

Sumber : Pengolah Data excel 
Setelah menghitung nilai rata-rata tersebut, maka peneliti akan menemukan hasil akhir nilai ratarata dari variabel Video Like dan Like, yaitu :

Tabel 6. Nilai Variabel Pada Akun TikTok 5 Brand Sepatu Olahraga di Dunia

Tabel Nilai Masing-Masing Variabel

\begin{tabular}{|l|r|r|r|r|r|}
\hline Variabel & \multicolumn{1}{|c|}{ Addidas } & \multicolumn{1}{|c|}{ Nike } & \multicolumn{1}{c|}{ Reebok } & New Belance & AirWalk \\
\hline Video Likes & 4340.075 & 2376.6 & 786.41 & 130.85 & 60.1 \\
\hline Likes Ratio & 33.800 & $4,700,000$ & $1,200,000$ & $1,300,000$ & 3441 \\
\hline
\end{tabular}

Sumber : Pengolah Data excel

Pada akun TikTok terdapat 7 Ratı yang relevan digunakan untuk mengukur kredibilitas pada masing-masing akun. Namun pada penelitian kali ini hanya berfokus untuk menghitung Video Like to Like Ratio. Untuk menghitung kredibilitas dari masing-masing akun TikTok setiap brand sepatu olahraga, peneliti menghitung dengan cara : variabel 1 akan dibagi dengan variabel 2, sehingga ditemukan hasil analisisa dari Ratio tersebut.

Tabel 7. Hasil Perhitungan Rasio Akun TikTok

Tabel Ratio

\begin{tabular}{|l|c|c|c|c|c|}
\hline \multicolumn{1}{|c|}{ Ratio } & Addidas & Nike & Reebok & New Belance & AirWalk \\
\hline $\begin{array}{l}\text { Video Like \& Like } \\
\text { Ratio }\end{array}$ & 128.4045858 & 0.00050566 & 0.000655342 & 0.000100654 & 0.017465853 \\
\hline
\end{tabular}

Sumber : Pengolah Data excel

Video Like to Like Ratio memiliki karakteristik yang tinggi, artinya semakin tinggi nilai yang dihasilkan maka semakin baik kredibilitas dari performa akun tersebut. Untuk memberikan peringkat pada masing-masing Brand Sepatu Olahraga, peneliti memberikan angka 5 kepada Brand Sepatu Olahraga yang mendapatkan nilai tertinggi dan angka 1 untuk Brand Sepatu Olahraga yang mendapatkan nilai terendah. Berikut merupakan tabel urutan nilai yang dihasilkan oleh masing-masing Brand. 
Tabel 8. Peringkat Ratio Akun TikTok 5 Brand Sepatu Olahraga di Dunia

\section{Tabel Peringkat}

\begin{tabular}{|c|c|c|c|c|c|}
\hline Ratio & Addidas & Nike & Reebok & New Belance & AirWalk \\
\hline Video Like \& Like Ratio & 5 & 4 & 3 & 1 & 2 \\
\hline
\end{tabular}

Sumber : Pengolah Data excel

Dari Tabel Peringkat Ratio Akun TikTok 5 Brand Sepatu Olahraga di Dunia dapat dsimpulkan bahwa akun TikTok Addidas mendapatkan nilai tertinggi untuk ratio Video Like to Like. Sedangkan akun TikTok New Belance mendapatkan nilai terendah untuk ratio ini. Jadi, pada penelitian ini akun TikTok Addidas memiliki kredibilitas performa yang lebih baik dibandingkan dengan Brand Sepatu Olahraga yang lainnya. 


\section{BAB V \\ KESIMPULAN}

Tujuan dari penelitian ini adalah untuk mengetahui kredibilitas performa dari akun TikTok 5 Brand Sepatu Olahraga di Dunia menggunakan Video Like to Like Ratio. 5 Brand Sepatu Olahraga di Dunia tersebut diantaranya :Addidas, Nike, Reebook, New Belance, dan Airwalk. Dari kelima Brand Sepatu Olahraga tersebut dapat disimpulkan bahwa :

1. Peringkat pertama diraih oleh Brand Adidas dengan nilai tertinggi yaitu 128.4045858

2. Peringkat kedua diraih oleh Brand Airwalk dengan nilai 0.017465853

3. Peringkat ketiga diraih oleh Brand Reebok dengan nilai 0.000655342

4. Peringkat keempat diraih oleh Brand Nike dengan nilai 0.00050566

5. Peringkat kelima diraih oleh Brand New Belance dengan nilai terendah yaitu 0.000100654 


\section{DAFTAR PUSTAKA}

Bali.transstudiomall, 5 Brand Sepatu Olahraga di Dunia,

https://bali.transstudiomall.com/page/content/91/5-merk-sepatu-olahraga-terbaik-yangbikin-kamu-tampil-semakin-sporty-dan-kece

bambang winarso 2021. "Apa Itu TikTok dan Apa Saja Fitur-fiturnya?".

Batam, Universitas Internasional. 2020. "ANALISIS FENOMENA SOSIAL MEDIA DAN KAUM MILENIAL : STUDI KASUS TIKTOK” 1: 565-72.

Cahyono, A. S. 2016. "Pengaruh media sosial terhadap perubahan sosial masyarakat di Indonesia". Jurnal ilmu sosial \& ilmu politik diterbitkan oleh Fakultas Ilmu Sosial \& Politik, Universitas Tulungagung, $9(1)$.

Chusna, P. A., Zakiyah, D., dkk. 2020. Analisis Dampak Fenomena Aplikasi Tik Tok Dan Music Dj Remix Terhadap Penyimpangan Perilaku Sosial Pada Anak Usia Sekolah Dasar. Jurnal Studi Islam Al-Fikrah, 4.

I Putu Hendika Permana, dan Ni Putu Suci Meinarni 2021. "Ratio Analysis on Tiktok (Social Media) for Qualitative Research Using Explorative Methods". Jurnal Ekonomi \& Bisnis JAGADITHA, 8(1), 30-38. https://doi.org/10.22225/jj.8.1.2944.30-38.

Karunia H, H., Ashri, N., dkk. 2021. "Fenomena Penggunaan Media Sosial : Studi Pada Teori Uses and Gratification". Jurnal Teknologi Dan Sistem Informasi Bisnis, 3(1), 92-104. https://doi.org/10.47233/jteksis.v3i1.187.

Mana, L. H. A. 2021. "RESPON SISWA TERHADAP APLIKASI TIKTOK SEBAGAI MEDIA PEMBELAJARAN BAHASA INDONESIA". JIRA: Jurnal Inovasi dan Riset Akademik, 2(4), 428-429. https://doi.org/10.47387/jira.v2i4.107.

Nasution, S. 2017. "Variabel penelitian". Raudhah, 05(02).

Nusantara, C. A. 2021. "TRATEGI DIGITAL MARKETING UNTUK MENINGKATKAN PENJUALAN BISNIS ONLINE MELALUI APLIKASI TIKTOK TUGAS EAS TECHNONOPRENEURSHIP DIGITAL CONTENT (A)". TRATEGI DIGITAL MARKETING UNTUK MENINGKATKAN PENJUALAN BISNIS ONLINE MELALUI APLIKASI TIKTOK TUGAS EAS TECHNONOPRENEURSHIP DIGITAL CONTENT (A).

Wijaya, Mukhammad Handy dwi, and Musta'in Mashud. 2020. "Konsumsi Media Sosial Bagi Kalangan Pelajar: Studi Pada Hyperrealitas Tik Tok.” Al-Mada: Jurnal Agama, Sosial, Dan Budaya 3 (2): 170-91. 